\title{
A ROMARIA DO DIVINO PAI ETERNO
}

Silvana Nascimento*

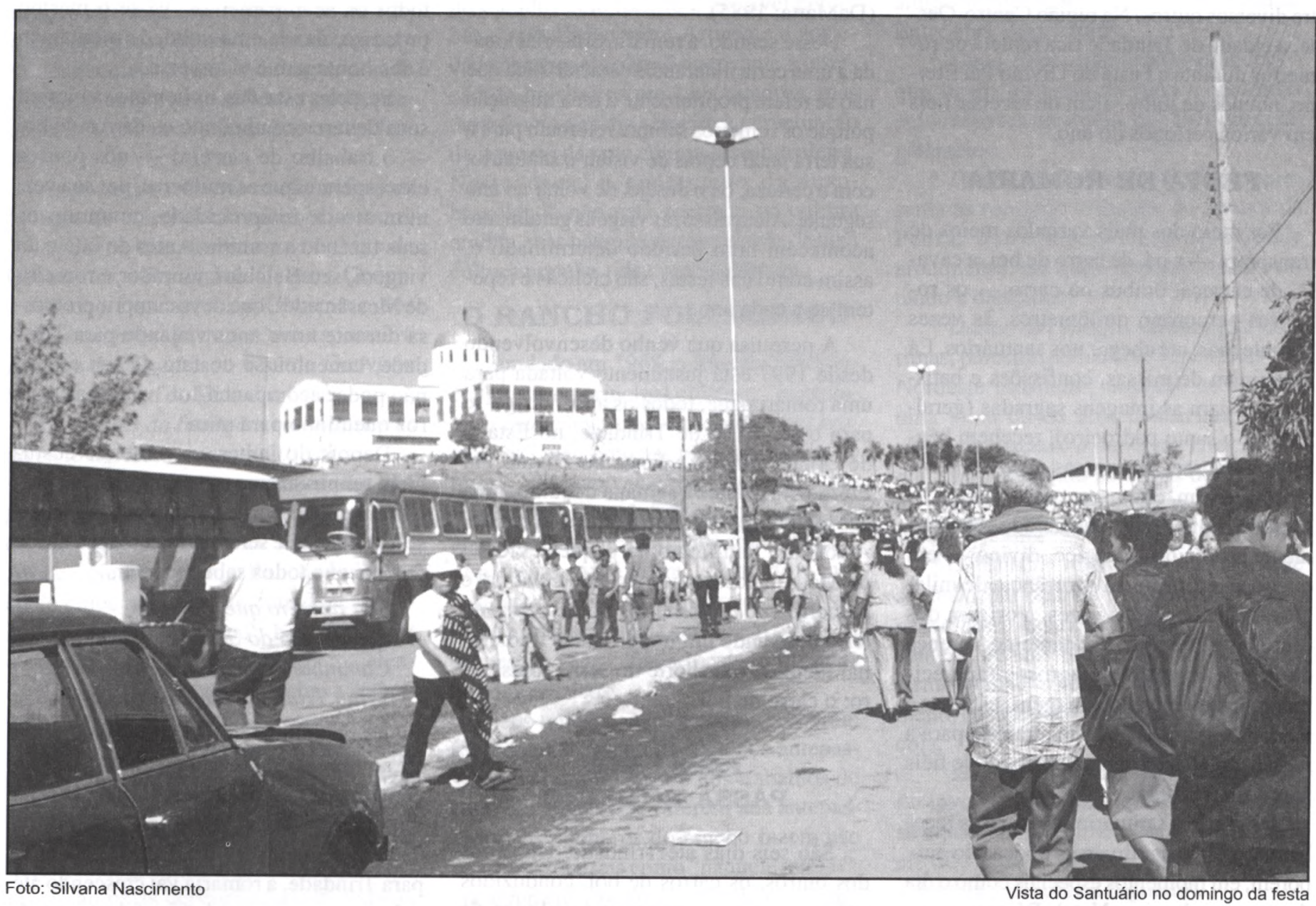

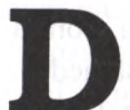
as passarelas das escolas de samba aos terreiros de candomblé, das festas de santo às comemorações do Dia da Independência, das pequenas comunidades às grandes cidades, no Brasil festejam-se todos os dias, todos os meses. Por algum motivo vai-se à festa, seja para dançar, desfilar, cantar; seja para louvar ao santo padroeiro, cumprir promessas, comemorar datas importantes.

Particularmente nas festas do catolicismo popular espalhadas pelo país (festas de São Benedito, São João, Nossa Senhora Aparecida, Santa Cruz, do Divino, São Se- bastião, Santo Antônio, entre outras), a importância do deslocamento mostra-se, de uma forma ou de outra, fundamental. É preciso, antes de mais nada, "ir à festa". Como diria o antropólogo Carlos Rodrigues Brandão, "crer é no imóvel, mas rezar é para quem se move" (1989: p. 25).

Nas Folias do Divino e nas Folias de Reis, visitam-se as casas da comunidade para o anúncio dos festejos e para um convite ritual aos moradores para a participação nas comemorações, ao som de cantos, rezas e violas. Na Festa de Santa Cruz, na Aldeia de Carapicuíba, próxima à capital de São Paulo, por exemplo, realiza-se uma pequena viagem pela aldeia, onde se dança três dias e três noites, nos primeiros dias de maio, em frente às casas para festejar a Santa Cruz e a comunidade festeira.

Mas, entre as incontáveis festas populares, é nas romarias que esse deslocamento tem um significado especial. Milhares de pessoas saem de suas cidades em direção aos santuários, principalmente durante as ocasiões festivas. O santuário de Nossa Senhora Aparecida, a padroeira nacional, no Estado de São Paulo, é famoso por receber romeiros de todo o Brasil não ape- 
nas durante a festa da padroeira em outubro mas em todos os finais de semana. A devoção ao Padre Cícero atrai fiéis de diversas regiões do Nordeste para Juazeiro do Norte, no Ceará.

Existem, ainda, santuários como o de Pirapora do Bom Jesus, em São Paulo; São Francisco das Chagas de Canindé, no Ceará; Nossa Senhora da Penha, no Rio de Janeiro; Bom Jesus da Lapa, na Bahia, entre diversos outros. Na região Centro-Oeste, a cidade de Trindade fica repleta de romeiros durante a Festa do Divino Pai Eterno, no mês de julho, além de receber fiéis em vários períodos do ano.

\section{FESTA DE ROMARIA}

Por meio dos mais variados meios de transporte - a pé, de carro de boi, a cavalo, de carroça, ônibus ou carro - os romeiros percorrem quilômetros, às vezes durante dias, até chegar nos santuários. Lá participam de missas, confissões e batismos, visitam as imagens sagradas (geralmente do santo padroeiro), recebem bênçãos, cumprem promessas e fazem penitências; enfim, entram em contato com "o sagrado" num lugar considerado especialmente propício - mágico, divino - em que se acredita até na ocorrência de milagres. Na maioria das vezes, a origem dos santuários está ligada justamente à crença de acontecimentos milagrosos (aparecimento inexplicável de imagens, estátuas e medalhões) que acabaram atraindo para a região um número cada vez maior de fiéis para visitar o lugar.

Os grandes santuários brasileiros recebem romeiros em diversas épocas do ano, porém, em momentos especiais como o dia do santo padroeiro, Natal, Páscoa, o número de devotos aumenta consideravelmente. Nestes períodos, os centros de devoção ganham outro caráter: o de uma grande festa.

Interessante notar que a festa não está limitada apenas ao lugar do santuário mas a toda uma rede que se estende aos preparativos dos romeiros em sua terra natal e, principalmente, à viagem até à "terra santa". O deslocar-se de um lugar a outro, da casa à festa, compreende uma dinâmica festiva que torna a jornada de peregrinação carregada de sacralidade e, ao mesmo tempo, de diversão e encontro entre pa- rentes, compadres, amigos e vizinhos.

Preenchendo de significados a trajetória que conduz ao santuário, a festa de romaria implica uma transformação de uma situação cotidiana para outra, temporária, deslocada do tempo e do espaço da rotina. Ela permite uma viagem - real e simbólica - que modifica, suspende a vida cotidiana para a criação momentânea de um outro mundo, especial, mágico, divino (DaMatta; 1985).

Nesse sentido, a romaria está relacionada a uma certa itinerância característica que não se refere propriamente a uma migração porque os romeiros sempre retornam para a sua terra natal depois de visitar o santuário, com a certeza, ou o desejo, de voltar no ano seguinte. Além disso, as viagens geralmente acontecem num período determinado e, assim como nas festas, são cíclicas e repetem-se a cada ano.

A pesquisa que venho desenvolvendo desde 1997 está justamente voltada para uma romaria que, todos os anos, dirige-se para o santuário de Trindade, no Estado de Goiás, durante a Festa do Divino Pai Eterno, na primeira semana de julho, uma das maiores e mais importantes da região. A romaria tem início na pequena cidade de Mossâmedes, a noroeste de Goiânia, e percorre 150 quilômetros por estradas de terra utilizando um importante e tradicional meio de transporte do sertão brasileiro: o carro de boi.

\section{PASSA BOI PASSA ROMEIRO}

São seis dias até Trindade. Uns atrás dos outros, os carros de boi, conduzidos pelos carreiros, carregam toneladas de mantimentos, bagagens, fogões e utensílios domésticos, mulheres e crianças. Percorrendo em média 25 quilômetros por dia, numa paisagem de cerrado que oscila entre plantações de cana-de-açúcar, pastos e pequenas cidades, as famílias romeiras moradores do meio rural no qual o trabalho está voltado para a pecuária extensiva (de corte e de leite) - viajam por antigas estradas de terra e, ao final de cada dia, acampam em fazendas. Cada grupo familiar (avôs, pais, cunhados, filhos e netos com suas esposas) faz a romaria um atrás do outro, formando uma grande caravana (em média 20 a 30 carros de boi, no caso de Mossâmedes).

Nos pousos, todos os dias, repetem-se as mesmas atividades. Quase tudo que estava dentro dos carros é retirado: colchões, sacolas de roupas, cobertores, bancos, latões de água, carne e outros mantimentos, panelas. $O$ fogão é colocado dentro da barraca, armada entre dois ou três carros, para o preparo das refeições pelas mulheres. Em todos os acampamentos, vê-se o mesmo processo, na ida e na volta, de montagem e desmontagem e vice-versa.

Se, pelas estradas, os homens cumprem seus deveres conduzindo os carros de boi - o trabalho de carreiro - nos pousos eles esperam que as mulheres, por sua vez, num ato de reciprocidade, cumpram os seus fazendo a comida. Antes do início da viagem, seu Belchior, morador e romeiro de Mossâmedes, que deve cumprir promessa durante nove anos viajando para Trindade, lamentou-se do fato de sua esposa não poder acompanhá-lo: "vai faltar o arroz quentinho para mim".

Depois do jantar, os romeiros costumam reunir-se para a reza: uma breve oração em que, durante toda a viagem, cantase a música que será ouvida no dia a dia da festa, e que todos sabem cantar.

\section{Sou romeiro que caminha \\ Sou devoto do Senhor \\ Caminhando pra terra santa \\ Velha Trindade da fé e do amor..}

No penúltimo dia da ida já se pode avistar ao longe o santuário no alto do morro, com quatro grandes naves formando uma cruz (a arquitetura desta igreja lembra a de Aparecida do Norte). De Mossâmedes para Trindade, a romaria vai crescendo até culminar com a entrada triunfal no santuário: um Desfile de Carros de Boi, com a participação de grupos de Mossâmedes, Anicuns, Americano, Damolândia, Cedro, Capela, Sancrerlândia, Itaberaí, Petrolina de Goiás, Santa Bárbara, São Francisco, Inhumas, Goianira, Araçu, Caturaí, Turvânia, Ouro Verde, Campestre, Palmeiras, Ordália, Nova Veneza e Morrinhos. E todos usando carros de boi.

\section{A ROMARIA NA FESTA}

Trindade, com pouco mais de $50 \mathrm{mil}$ habitantes, transforma-se durante esses 


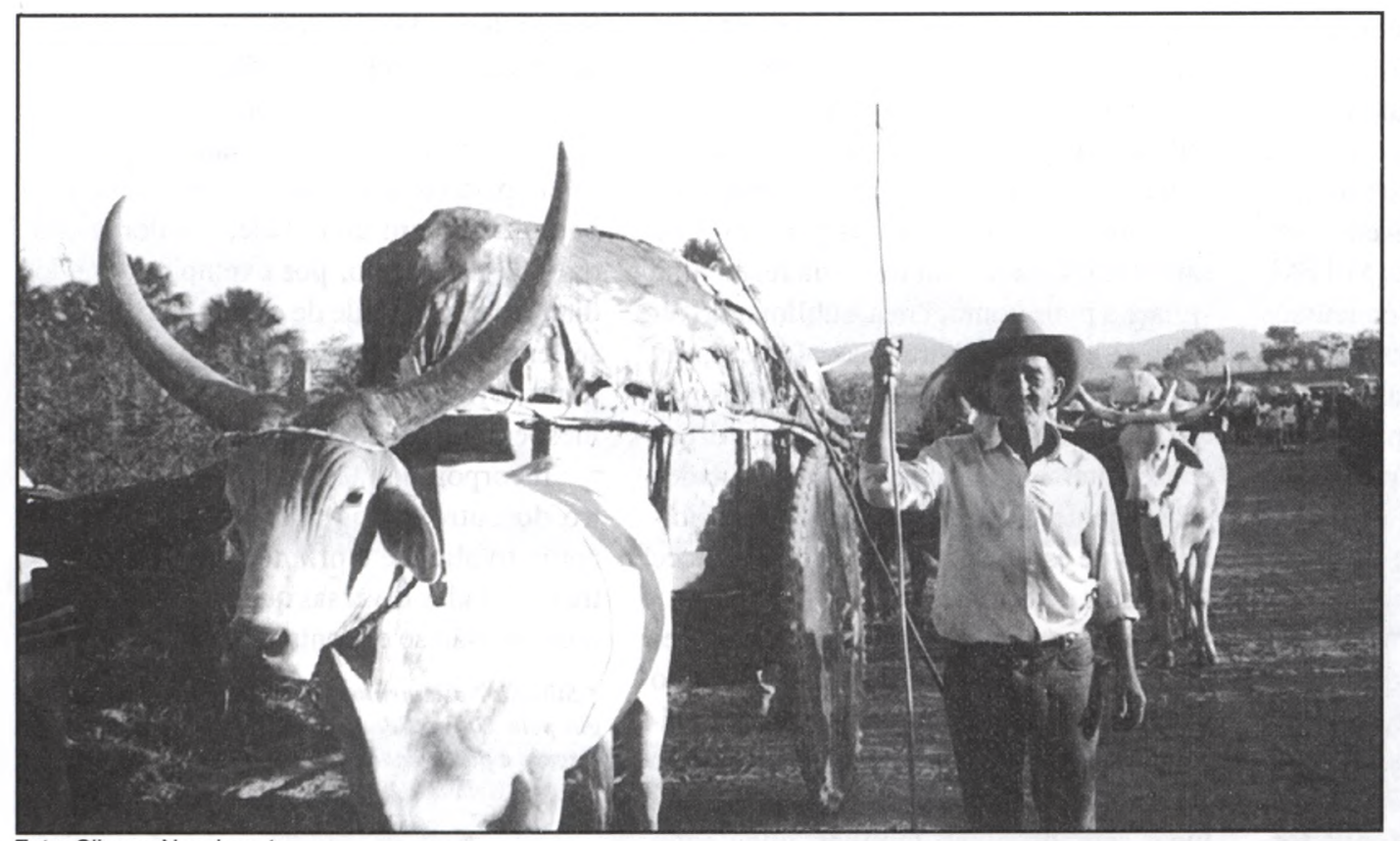

se assistindo às imagens dos carros de boi, da cidade cheia de romeiros, das igrejas etc.

Este interessante aspecto multimídia da festa também se expressa por uma homepage do santuário do Divino Pai Eterno na internet. Pelo endereço hhtp:www.persogo.com.br/ sdpaieterno, temos acesso ao informativo mensal do santuário, a uma breve história de Trindade e a uma seção para correspondências (e-mail: sdpaieterno@persogo.com.br).

Ao assistir às fitas que são vendidas na Sala dos Milagres e em outras barracas espalhadas pelo santuário, pode-se perceber que as romarias de carro de boi são a atração principal.

dias numa festa gigantesca, recebendo de 300 a 400 mil pessoas, entre as quais dez mil chegam em carros de boi. A Festa do Divino Pai Eterno acontece na primeira semana de julho e comemora, oficialmente, para os missionários redentoristas responsáveis pelo santuário, o dia da Santíssima Trindade, um domingo depois de Pentecostes (cinquenta dias depois da Páscoa).

As histórias sobre a origem do santuário remontam a 1840 , quando um casal de camponeses encontrou um medalhão de barro enquanto roçava o pasto num arraial chamado Barro Preto. O objeto trazia a imagem da Virgem Maria coroada pela Santíssima Trindade: o Pai de um lado, o Filho de outro e o Espírito Santo iluminando Maria, de cima, simbolizado por uma pomba branca.

A festa, então, não celebra somente o dia oficial da Trindade mas a própria origem do santuário e da crença dos seus inúmeros devotos. Na região Centro Oeste, a devoção ao Divino Pai Eterno tem quase o mesmo peso que a da padroeira nacional de Nossa Senhora Aparecida, centralizada em Aparecida do Norte. Aliás, tanto o santuário de Trindade como o de Aparecida são dirigidos por missionários redentoristas desde o final do século XIX.

Diferentemente das festas de romaria que acontecem nas estradas, condensadas a uma determinada região ou cidade, a festa em Trindade reúne romeiros das mais di- versas regiões que acabam se diluindo na multidão. Não há espaço para todos, nem acampamentos suficientes para aqueles que vêm de lugares distantes. Centenas de pedintes instalam-se na porta das duas igrejas para pedir esmolas. As ruas ficam abarrotadas de barraquinhas que vendem produtos para todas as idades, gostos e necessidades.

Para visitar a imagem do Divino Pai Eterno dentro da Igreja Matriz e na Igreja nova é necessário entrar numa fila, que no último dia da festa de 1997 atravessava quatro quarteirões para entrar na Matriz, debaixo de muito sol. É o conhecido "beijamento": os devotos beijam fitas amarradas ao pé da imagem, rezam e escrevem seus pedidos.

Como todo santuário, há também a famosa "Sala dos Milagres" que, em Trindade, apresenta características muito peculiares. Além das fotografias, quadros, peças de cera, pedaços de cabelo, muletas, cadeiras de roda, bandeiras, cartas, que costumamos encontrar em qualquer sala dos milagres em outros santuários brasileiros, existem stands com projeções de vídeo das romarias e da festa em Trindade organizadas por empresas especializadas. Assim, ao mesmo tempo em que o devoto pode sensibilizar-se observando os objetos expostos na sala - legitimando as promessas cumpridas e pedidos feitos ao "Divino Pai Eterno" - pode também distrair-
Já no início da festa, há um desfile de carros de boi que chama a atenção de milhares de devotos. E estes romeiros (os carreiros) têm um espaço reservado para o acampamento, cedido pela prefeitura de Trindade.

Durante os dias da festa no santuário, os carreiros de Mossâmedes, que tive a oportunidade de acompanhar, aproveitaram plenamente das atividades oferecidas: celebrações, compras e muita diversão. Mais do que isso, durante esta festa, como moradores do meio rural, eles têm acesso a bens materiais e simbólicos típicos das grandes cidades.

Paralelamente às missas (de hora em hora) e procissões da penitência (todas as manhãs), atividades religiosas oferecidas pelos redentoristas, os romeiros tiveram a oportunidade de entrar em contato com as mais diversas novidades do mercado: fitas cassete de cantores de música sertaneja, os mais variados aparelhos eletrônicos, roupas, sapatos, chapéus com designs mais tradicionais ou mais modernos ao estilo country; todos os utensílios domésticos para montar uma cozinha; bijuterias; brinquedos, etc. Passeando por um imenso "shopping center mambembe" que preenche as ruas, esquinas, calçadas, na verdade, um grande "camelódromo", eles podem se abastecer de bens - pelo menor preço e maior variedade de escolha que normalmente não têm acesso nas pe- 
quenas cidades ou comunidades rurais onde moram, como Mossâmedes.

Nesse sentido, além do contato com "o sagrado" na terra santa, Trindade oferece um banho de "cidade". Durante o dia, dois parques de diversões animam jovens e crianças. À noite, locutores da rádio Mil FM, de Goiânia, comandam shows, concursos de calouros e videoclips em dois telões, um de cada lado do palco, localizado ao lado da Igreja Matriz. No ano passado, o slogan dos animadores era: "Trindade, a capital da fé".

Não se pode esquecer que, paralelamente a esta agitação "metropolitana" no centro da cidade, nos acampamentos, as mulheres, numa "casa" provisória, improvisada entre um passeio e outro, preparavam as refeições para as famílias, lavavam roupas em bacias, varriam o chão de terra batida, cuidavam dos filhos. De certa forma, continuavam trabalhando nas mesmas atividades domésticas da vida cotidiana, no tempo e no espaço extraordinário da festa.

Os homens, por sua vez, com seus bois reunidos em pastos nas redondezas, assessoravam suas esposas carregando latões de água para as barracas ou comprando alguma mistura para a comida. Ou seja, suspendiam o trabalho rotineiro - de carreiro, que conduz os bois - até o fim da festa no santuário.

Terminadas as comemorações do Divino Pai Eterno, os romeiros acampados, enfim, retornaram para suas casas, pelos mesmos caminhos da ida, fazendo praticamente o mesmo percurso, na expectativa de retornar no próximo ano.

\section{UM MUNDO DENTRO DO OUTRO}

Da casa à festa, deslocando-se 150 quilômetros em carros de boi na ida e na volta, a romaria de Mossâmedes atravessa múltiplos domínios: do sagrado ao secular, do tradicional ao moderno, do regional ao nacional, do campo à cidade. De modo geral, este caráter ambíguo, seguindo a interpretação de Victor Turner (1974), mostra-se como um dos aspectos fundamentais da peregrinação (ou romaria). Isto se deve à sua posição liminar, que oscila entre universos de significado distintos.

Por alguns dias, numa temporalidade especial e única, de acordo com este autor, vivencia-se uma experiência de communitas, que atenua as diferenças da vida social. Assim, todos os participantes tornam-se, momentaneamente, "romeiros", ou ainda "devotos", unidos pela festa no santuário. Cria-se, em torno da festa, uma situação mais homogênea, sublimando diferenças sociais, culturais, econômicas, etc. Para Turner, a noção de communitas põe em questão a estrutura social (padrões conscientemente reconhecidos e regulados socialmente) apresentando novas possibilidades de estilo de vida. É o que acontece nas festas de romaria.

Nelas, o romeiro transpõe a vida sedentária da rotina, tanto no campo como na cidade, para um nomadismo temporário durante a jornada de peregrinação. Ele sai de um local familiar, dirige-se para um lugar sagrado e não familiar, onde entra em contato com novas possibilidades, sagradas e profanas, de vida social para, posteriormente, retornar ao local familiar, a sua casa. A trajetória, nesse sentido, está carregada de magia e sacralidade na qual o peregrino acredita atingir um "estado de graça", na esperança de vivenciar uma experiência direta com o sagrado.

Além disso, a viagem de romaria permite reforçar laços familiares e de solidariedade pelo intenso convívio entre parentes, compadres e vizinhos. E, ao mesmo tempo, tecendo uma vasta rede de relações sociais, mostra a possibilidade de uma vida social às avessas no tempo e no espaço da festa: de uma vivência urbana e metropolitana para os que vivem no meio rural e, para quem vem da cidade, a valorização da vida no campo, por exemplo, quando diante de um desfile de carros de boi. Nesse sentido, navegando entre universos distintos, a romaria propicia a experiência do inesperado, do extraordinário.

Incorporando, enfim, um mundo dentro do outro, a romaria apreende a festa como totalidade e promove o diálogo entre realidades diversas que, em outros momentos, não se encontrariam.

* Silvana Nascimento é mestranda em Antropologia pela Universidade de São Paulo, bolsista da Fapesp e pesquisadora do NAU (Núcleo de Antropologia Urbana/USP).

\section{REFERÊNCIAS BIBLIOGRÁFICAS}

BRANDĀO, Carlos Rodrigues

(1989) A Cultura na Rua. Campinas, Papirus. DAMATTA, Roberto

(1985) A Casa e a Rua. São Paulo, Brasiliense. MAGNANI, José Guilherme e TORRES, Lilian (orgs.).

(1996) Na Metrópole. São Paulo, Edusp,

SANCHIS, Pierre

(1983) Arraial: Festa de um Povo - As romarias portuguesas. Lisboa, Dom Quixote.

TURNER, Victor

(1974) "Pilgrimages as Social Process". Dramas, Fields and Metaphors. EUA, Ithaca.

Foto: Silvana Nascimento

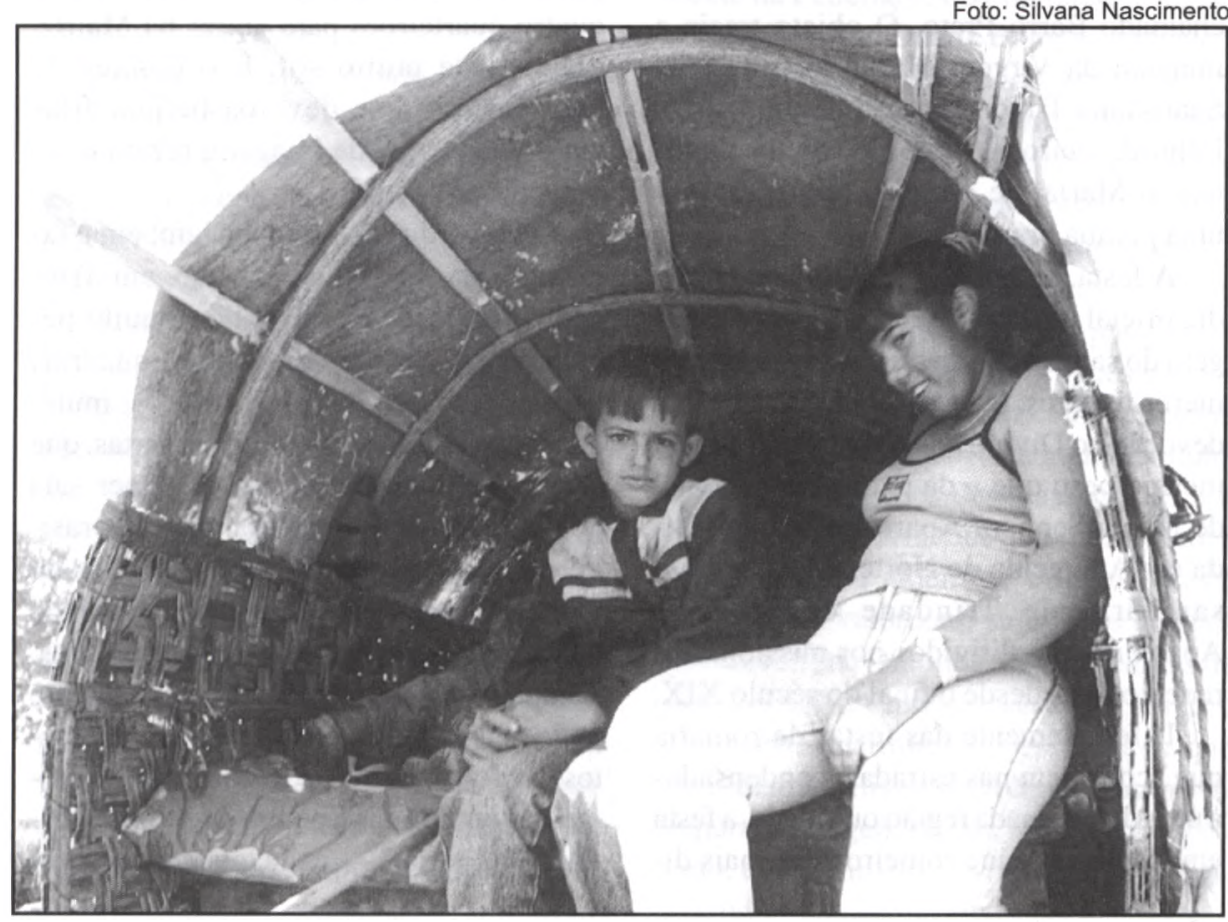

